\title{
Preface: New challenges for tsunami science: understanding tsunami processes to improve mitigation and enhance early warning
}

\author{
Héléne Hébert ${ }^{1}$, Ira Didenkulova ${ }^{2,3}$, Hermann M. Fritz ${ }^{4}$, and Gerassimos A. Papadopoulos ${ }^{5}$ \\ ${ }^{1}$ CEA, DAM, DIF, 91297 Arpajon, France \\ ${ }^{2}$ Nizhny Novgorod State Technical University n.a. R.E. Alekseev, Nizhny Novgorod, Russia \\ ${ }^{3}$ Marine Systems Institute, Tallinn University of Technology, Tallinn, Estonia \\ ${ }^{4}$ Georgia Institute of Technology, School of Civil and Environmental Engineering, Atlanta, GA 30332, USA \\ ${ }^{5}$ Institute of Geodynamics, National Observatory of Athens, Athens, Greece \\ Correspondence to: Héléne Hébert (hjlhebert@yahoo.fr)
}

Published: 10 August 2016

The special issue (SI) "New challenges for tsunami science: understanding tsunami processes to improve mitigation and enhance early warning" consists of selected papers presented at the EGU 2012 General Assembly in the three sessions dealing with tsunamis, namely the sessions "Large Earthquake and Tsunami Activity", "New developments in tsunami science and in mitigation of tsunami risk, including early warning", and "Early warning systems for natural hazards and risks". The SI papers treat different aspects of tsunami propagation, tsunami risk assessment, tsunami detection and forecast, including the progress on tsunami early warning systems.

The videos of the overland flooding of 2011 Japan tsunami feature the incorporation of solids within the flow column, which may consist of either sediment from the natural environment or debris from the built infrastructure (Fritz et al., 2012). In this SI, a model capable of dealing with such a complicated behavior of tsunami currents is presented by Conde et al. (2013). They show that their 2-DH (twodimensional horizontal) mathematical model is particularly suited for tsunami propagation over complex and dynamic geometries, such as river and estuarine mobile beds. The discretization scheme is based on a finite-volume method using a flux-splitting technique featuring a reviewed Roe's Riemann solver, with appropriate source-term formulations to ensure full conservativeness. The model is validated with laboratory data and paleo-tsunami evidence. As a forecasting application, it is applied to a tsunami scenario in the Tagus estuary in Portugal. This effort is justified by the documented catastrophic tsunamis that struck this location over the past two millennia. The obtained results show that, despite the significant differences in Lisbon's layout and morphology, a 1755-like tsunami would still inflict a devastating impact on this major city today.

"Slow" or "tsunami" earthquakes produce tsunamis disproportionately large with respect to their seismic moment (Kanamori, 1972). Two such tsunami events occurred off the Pacific coast of Central America with the 1992 Nicaragua and 2012 El Salvador slow earthquakes (Borrero et al., 2014). In this SI Álvarez-Gómez et al. (2013) conducted tsunami hazard assessment for El Salvador, which is the smallest and most densely populated country in Central America. In El Salvador there were 15 recorded tsunamis between 1859 and 2012, 3 of them causing damages and resulting in hundreds of victims. Hazard assessment is commonly based on numerical models for earthquake-generated tsunami propagation and can be approached through both probabilistic and deterministic methods. A deterministic approximation has been applied by Álvarez-Gómez et al. (2013) as it provides essential information for coastal planning and management. The objective of the research was twofold: on the one hand, the characterization of the threat over the entire coast of El Salvador and, on the other, the computation of flooding maps for the three main localities of the Salvadorian coast. The results show that at the western Salvadorian coast, run-up values higher than $5 \mathrm{~m}$ are common, while in the eastern area, approximately from La Libertad to the Gulf of Fonseca, the run-up values are lower. The areas more exposed to flooding are the lowlands in the Lempa River delta and the Barra 
de Santiago Western Plains. Inside the Gulf of Fonseca the impact of the waves is almost negligible.

Tsunami propagation is usually modeled either by shallow water or Boussinesq equations. The former is usually applied to seismic tsunamis, while the latter is used to describe tsunamis of landslide and volcanic origins, where dispersion can play an important role. In this SI Glimsdal et al. (2013) investigate the situations when dispersive effects become significant. To this aim they apply a single parameter called "dispersion time", which characterizes the influence of dispersion on wave propagation and depends on the wavelength, the water depth, and the propagation distance or time. This parameter can be useful as a first indication when frequency dispersion is important, even though ambiguity with respect to the definition of the wavelength may be a problem for complex cases. Tsunamis from most landslides and moderate earthquakes tend to display dispersive behavior, at least in some directions. On the other hand, for the mega-events of the last decade such as the 2004 Indian Ocean and 2011 Japan tsunamis, dispersion during deep water propagation is mostly noticeable for transoceanic propagation.

Tsunami warning systems have been advanced in the aftermath of the 2004 catastrophe in the Indian Ocean. Their first task, in the case of any tsunamigenic earthquake, is the early characterization of the seismological parameters, mostly based on the early inversion of seismic data. However dense networks of GPS sensors, such as the GeoNet network deployed in Japan for many years, open the possibility to provide a real-time detection of the coseismic deformation independently of the seismic data (see the paper in this SI by Hoechner et al., 2013). Although the sensors are deployed on land, during the first $60-100$ s of the 2011 Tohoku rupture, they captured the large crustal deformation on vertical and horizontal components, ranging in amplitude from several centimeters to about one meter. When coupled to a tsunami model, implying a slip inversion in this study, the a posteriori analysis show that such an early warning technique would have provided the maximum warning level for the coasts of the Tohoku area within 180 s of the 2011 rupture. In the future, the improvements of real-time GPS data processing, associated with a densification of the GPS coastal networks, may offer a promising perspective for warning systems monitoring large submarine earthquakes.

Tsunami modeling is also continuously improving along with increasing computing capacities, and this offers an exciting perspective not only for hazard studies but also for operational purposes. Tsunami early warning systems (TEWSs) now take more and more advantage of improved numerical techniques. However, despite enhanced numerical performance, most TEWSs still rely on precomputed databases, all the more when the expected threat is in the near field. For instance, as it is shown in this SI, in the Indian Ocean and specifically in Indonesia (Rakowsky et al., 2013) the TsunAWI code has been used to design a tsunami database consisting of about 3500 scenarios for $M_{\mathrm{w}}$ magnitudes in the range of 7.5-9.0. The selection of scenarios in real time relies on the location of the epicenter, with uncertainties accounted for within an ellipsis whose extension depends on the magnitude, and rapidly providing coastal tsunami heights. In addition TsunAWI also allows computing hazard maps showing for instance the effect of bottom friction. Nevertheless, tsunami modeling "on the fly" is still challenging, and some innovative numerical approaches are currently explored, such as easyWave using GPU architecture (see for example Hoechner et al., 2013).

The same conclusion can be drawn in the western Mediterranean basin where precomputed tsunami databases have also been implemented in operational context, which is described in this SI (Gailler et al., 2013). The approach is different since a series of unit tsunamis has been defined with the purpose of building a composite scenario as a linear combination, with a number of scenarios depending on the magnitude. The range of possible aggregated magnitudes is from 6.5 to 8.0. The unit scenarios rely on the state of the art of active tectonics. The advantage is to provide global hazard maps at the basin scale taking into account uncertainties on the epicenter and the magnitude, in a context somehow more complex than a large subduction zone. These regional maps help to define the regions at risk. However, they do not provide a detailed coastal forecast which would require considering nonlinear effects. As in the Indonesian context, the coastal forecasting is evolving, but this aspect still requires high-resolution coastal bathymetry in many places, as well as addressing uncertainties in the seismological parameters as early as possible.

Sometimes assessments of coastal hazards are based on simple theoretical estimates of wave run-up, often obtained under plane beach assumptions (Harbitz et al., 2012). However, the real bottom bathymetry and coastline topography is much more complicated and can lead to resonant effects. In this SI, Ezersky et al. (2013) study these effects in a schematized beach profile consisting of three pieces of constant but different slopes. They show that even such simple variations of bottom profile can lead to significant increase of wave height, particle velocity, and number of oscillations.

Extensive modeling techniques used in modern TEWSs can be greatly complemented by real-time instrumental tsunami detection and "on the spot" identification. This is particularly important for tsunamis of nonseismic origin, which are not considered by the currently operating TEWSs. The need to identify tsunamis as soon as possible stimulated the development of tsunami detection algorithms along with new tsunami measurement techniques. Among the most recent efforts are the tsunami detection algorithms for highfrequency radar installations (Lipa et al., 2012), for BPR sensors (Beltrami, 2011), for coastal tide gauges (Bressan and Tinti, 2011) and also for wind wave measurements (Beltrami and Di Risio, 2011). All the suggested techniques aim to distinguish the tsunami signal from the ambient wave background, which can be highly elaborated due to the impact 
of tides, infra-gravity waves, seiches, storm surges, storm waves, and ship wakes. These techniques also strongly depend on the particular location of the measurement site. In this situation calibration is of high importance. In this SI Bressan et al. (2013) calibrate the suggested real-time tsunami early detection algorithm (TEDA) for two stations in eastern Sicily, Italy, and find the best configurations, which minimize the chances of no tsunami detection or of a false alarm for these two sites. They also demonstrate the efficiency of synthetic tsunami records as experimental data for locations with poor or non-existing tsunami records.

\section{References}

Álvarez-Gómez, J. A., Aniel-Quiroga, Í., Gutiérrez-Gutiérrez, O. Q., Larreynaga, J., González, M., Castro, M., Gavidia, F., Aguirre-Ayerbe, I., González-Riancho, P., and Carreño, E.: Tsunami hazard assessment in El Salvador, Central America, from seismic sources through flooding numerical models, Nat. Hazards Earth Syst. Sci., 13, 2927-2939, doi:10.5194/nhess-132927-2013, 2013.

Beltrami, G. M.: Automatic, real-time detection and characterization of tsunamis in deep-sea level measurements, Ocean Eng., 38, 1677-1685, 2011.

Beltrami, G. M. and Di Risio, M.: Algorithms for automatic, real time tsunami detection in wind-wave measurements Part I: Implementation strategies and basic tests, Coast. Eng., 58, 10621071, 2011.

Borrero, J. C., Kalligeris, N., Lynett, P. J., Fritz, H. M., Newman, A. V., and Convers, J. A.: Observations and Modelling of the August 27, 2012 Earthquake and Tsunami affecting El Salvador and Nicaragua, Pure Appl. Geophys., 171, 3421-3435, doi:10.1007/s00024-014-0782-2, 2014.

Bressan, L. and Tinti, S.: Structure and performance of a real time algorithm to detect tsunami or tsunami-like alert conditions based on sea-level records analysis, Nat. Hazards Earth Syst. Sci., 11, 1499-1521, doi:10.5194/nhess-11-1499-2011, 2011.

Bressan, L., Zaniboni, F., and Tinti, S.: Calibration of a realtime tsunami detection algorithm for sites with no instrumental tsunami records: application to coastal tide-gauge stations in eastern Sicily, Italy, Nat. Hazards Earth Syst. Sci., 13, 31293144, doi:10.5194/nhess-13-3129-2013, 2013.
Conde, D. A. S., Baptista, M. A. V., Sousa Oliveira, C., and Ferreira, R. M. L.: A shallow-flow model for the propagation of tsunamis over complex geometries and mobile beds, Nat. Hazards Earth Syst. Sci., 13, 2533-2542, doi:10.5194/nhess-132533-2013, 2013.

Ezersky, A., Tiguercha, D., and Pelinovsky, E.: Resonance phenomena at the long wave run-up on the coast, Nat. Hazards Earth Syst. Sci., 13, 2745-2752, doi:10.5194/nhess-13-2745-2013, 2013.

Fritz, H. M., Phillips, D. A., Okayasu, A., Shimozono, T., Liu, H., Mohammed, F., Skanavis, V., Synolakis, C. E., and Takahashi, T.: 2011 Japan tsunami current velocity measurements from survivor videos at Kesennuma Bay using LiDAR, Geophys. Res. Lett., 39, L00G23, doi:10.1029/2011GL050686, 2012.

Gailler, A., Hébert, H., Loevenbruck, A., and Hernandez, B.: Simulation systems for tsunami wave propagation forecasting within the French tsunami warning center, Nat. Hazards Earth Syst. Sci., 13, 2465-2482, doi:10.5194/nhess-13-2465-2013, 2013.

Glimsdal, S., Pedersen, G. K., Harbitz, C. B., and Løvholt, F.: Dispersion of tsunamis: does it really matter?, Nat. Hazards Earth Syst. Sci., 13, 1507-1526, doi:10.5194/nhess-13-15072013, 2013.

Harbitz, C., Glimsdal, S., Bazin, S., Zamora, N., Løvholt, F., Bungum, H., Smebye, H., Gauer, P., and Kjekstad, O.: Tsunami hazard in the Caribbean: Regional exposure derived from credible worst case scenarios, Cont. Shelf Res., 38, 1-23, 2012.

Hoechner, A., Ge, M., Babeyko, A. Y., and Sobolev, S. V.: Instant tsunami early warning based on real-time GPS - Tohoku 2011 case study, Nat. Hazards Earth Syst. Sci., 13, 1285-1292, doi:10.5194/nhess-13-1285-2013, 2013.

Kanamori, H.: Mechanism of tsunami earthquakes, Phys. Earth Planet. Inter., 6, 346-359, 1972.

Lipa, B., Isaacson, J., Nyden, B., and Barrick, D.: Tsunami arrival detection with high frequency (HF) radar, Remote Sens., 4, 1448-1461, 2012.

Rakowsky, N., Androsov, A., Fuchs, A., Harig, S., Immerz, A., Danilov, S., Hiller, W., and Schröter, J.: Operational tsunami modelling with TsunAWI - recent developments and applications, Nat. Hazards Earth Syst. Sci., 13, 1629-1642, doi:10.5194/nhess-13-1629-2013, 2013. 